\title{
OBTENCIÓN DE UNA BEBIDA NUTRITIVA A PARTIR DE LAS SEMILLAS DE SACHA INCHIC (Plukenetia volubilis L.)
}

\author{
Silvia Valles Ramírez*, Mari Medina-Vivanco ${ }^{1}$, Abner Obregón-Lujerio $^{1}$
}

\begin{abstract}
RESUMEN
Este trabajo tiene como objetivo elaborar una bebida nutritiva a partir de las semillas de sacha inchic (Plukenetia volubilis L.) como una alternativa a la leche de origen animal. Los parámetros evaluados fueron: i) la temperatura y el tiempo de pre tostado para eliminar la astringencia y ii) la relación ( $\mathrm{p} / \mathrm{v}$ ) almendra: agua para la obtención de la bebida nutritiva. Fueron realizados un análisis proximal de las almendras (semillas descascaradas) y la bebida nutritiva, y un perfil de ácidos grasos de la bebida nutritiva. Los resultados se analizaron utilizando un diseño completamente al azar con tres repeticiones. El mejor tratamiento de pre-tostado de las semillas fue $60{ }^{\circ} \mathrm{C}$ durante $6 \mathrm{~min}$. y la relación de almendra: agua más adecuada fue de 1:3. La bebida nutritiva de sacha inchic obtenida presentó 11,6\% de solidos totales, $3,3 \%$ de proteína, $7,13 \%$ de grasa y altos niveles de ácidos grasos esenciales $(30,9 \%$ de ácido linoléico y 42,19\% de ácido linolénico).
\end{abstract}

Palabras clave: Sacha inchic, proteína vegetal, ácidos grasos esenciales, bebida nutritiva.

\section{OBTAINING A NUTRITIOUS BEVERAGE FROM THE SEEDS OF INCA PEANUT (Plukenetia volubilis L.)}

\begin{abstract}
This work aims to elaborate a nutritious beverage from the seeds of inca peanut (Plukenetia volubilis L.) as an alternative to the consumption of animal milk. The evaluated parameters were: i) the temperature and the pre toasting time to eliminate the astringency and ii) the almond: water ratio (w/v) to obtain the nutritious beverage. Proximal analysis of the almonds (peeled seeds) and the nutritious beverage, and a fatty acids profile of the nutritious beverage were performed. The results were analyzed using a completely randomized design with three replicates. The best pre toasting treatment of the seeds was at $60{ }^{\circ} \mathrm{C}$ for $6 \mathrm{~min}$. and the best almond: water ratio was of $1: 3$. The sacha inchic whole beverage obtained contains $11.6 \%$ total solids, $3.3 \%$ protein, $7.13 \%$ fat and high levels of essential fatty acid $(30.9 \%$ linoleic acid and $42.19 \%$ linolenic acid).
\end{abstract}

Key words: Inka peanut, vegetable protein, essential fatty acids, nutritious beverage.

${ }^{1}$ Facultad de Ingeniería Agroindustrial, Universidad Nacional de San Martín, Jr. Amorarca s/n - Morales, Perú, silviamarisol@hotmail.com 


\section{INTRODUCCIÓN}

El género Plukenetia Linneo está constituido por 19 especies. En el Perú, una de las especies más reconocidas y que tiene una amplia distribución en la Amazonía peruana (Loreto, Ucayali, San Martín, Cusco, Madre de Dios, Amazonas, Junín y Pasco) es la especie Plukenetia volubilis Linneo, que crece entre los 30 a $2110 \mathrm{msnm}^{1}$. Los nombres populares que se les atribuyen a estas especies son sacha inchic, maní del inca, sacha maní o maní del monte y es utilizada como producto alimenticio por la población rural nativa ${ }^{2}$. En la actualidad la producción de sacha inchic continua en aumento por la demanda en los mercados internacionales; siendo el aceite extraído de las semillas, el principal producto por su alto contenido de ácidos grasos esenciales, además del snack y harina de la torta. Hay interés en desarrollar el componente proteína que contiene aminoácidos esenciales en cantidades adecuadas comparados con el patrón recomendado por la $\mathrm{FAO} / \mathrm{OMS}$ para una persona adulta (el triptófano es usualmente alto, $44 \mathrm{mg} / \mathrm{g}$ de proteína) $)^{3}$.

Las semillas de sacha inchic crudas presentan un sabor astringente, por la presencia de taninos que son sintetizados para la protección de agentes externos tales como insectos; que al ser ingeridos producen resequedad en la mucosa bucal y un sabor amargo. El tratamiento térmico es uno de los métodos utilizados para eliminar la astringencia de las semillas de sacha inchic ${ }^{4}$. Chirinos et al. ${ }^{5}$ estudiaron el impacto del tostado como tratamiento térmico sobre los ácidos grasos, tocoferoles y compuestos fenólicos presentes en las semillas de Plukenetia huallabambana para la elaboración de snacks, recomendando una temperatura de $100{ }^{\circ} \mathrm{C}$ por 10 min para la obtención de snacks con altos niveles de compuestos bioactivos y de alta estabilidad oxidativa.

La bebida nutritiva de sacha inchic es un producto que todavía no ha sido estudiado en profundidad. Sin embargo, existen metodologías para la elaboración de bebidas de otras fuentes oleaginosas, como la metodología para la obtención de la bebida del extracto de soya, que consiste en la cocción por ebullición de granos descascarados durante $30 \mathrm{~min}$. con adición de bicarbonato de sodio a $0,25 \%$ y una relación de $1: 3(\mathrm{p} / \mathrm{v})$; la finalidad es eliminar el sabor indeseable en la boca, también conocido como "chalkness", que es ocasionado por partículas de fibra proveniente de la soya; luego, los granos de soya son triturados con agua en una relación 1:15 (p/v) y homogeneizado a $4000 \mathrm{psi}^{6}$

El presente estudio propone la obtención de una bebida nutritiva a partir de las semillas de sacha inchic, que aporta ácidos grasos esenciales y proteínas, con buenas características sensoriales, y técnicamente podría suplir las carencias nutricionales de la población rural. 


\section{MATERIALES Y MÉTODOS}

\section{Materia prima}

Se emplearon semillas de sacha inchic del ecotipo Apangura, recolectadas en el distrito de Lamas, San Martín, Perú. Se caracterizó la almendra (semilla descascarada) mediante análisis proximal (humedad, proteína, grasa, fibra, ceniza y carbohidratos) según las recomendaciones de la $\mathrm{AOAC}^{7}$

\section{Etapas para la obtención de la bebida nutritiva de sacha inchic}

- Acondicionamiento y pre-tostado de las semillas

El acondicionamiento consistió en separar impurezas, polvo y arena provenientes de la zona de recolección. Seguidamente, se hizo un oreado por $24 \mathrm{~h}$ a temperatura ambiente. Durante el pre-tostado, $250 \mathrm{~g}$ de semillas de sacha inchic fueron colocadas en un perol de aluminio, a temperatura de 60 y $80^{\circ} \mathrm{C}$ por tiempos de 4,5 y 6 min.

\section{- Descascarado}

Las almendras se separan de la cáscara en forma manual aplicando un golpe suave. Además, fueron retiradas las semillas con daño físico (con vanos, hongos o apolilladas).

\section{- Molienda húmeda}

Esta operación se llevó a cabo con la finalidad de desintegrar la almendra. Para ello se usó una licuadora semi-industrial. La almendra fue licuada con agua durante $15 \mathrm{~min}$., formándose una suspensión lechosa y homogénea. Se evalúa la relación almendra: agua $(\mathrm{p} / \mathrm{v})(1: 3 ; 1: 4 ; 1: 5)$ $(\mathrm{g} / \mathrm{mL})$, cuantificando las propiedades físico-químicas (sólidos totales, densidad, viscosidad aparente y acidez titulable).

\section{- Tamizado y pasteurizado}

Se separó el residuo insoluble (torta) del extracto hidrosoluble (bebida nutritiva), usando tamiz malla $\mathrm{N}^{\mathrm{o}} 40$ y luego se pasteuriza a $75^{\circ} \mathrm{C}$ por $15 \mathrm{~min}$.

\section{- Estabilizado y envasado}

Para la estabilización de la bebida nutritiva se usó $2 \%$ de goma xantana (Keltrol F), envasado en caliente en botellas de plástico limpias y esterilizadas. El sellado se realizó de forma manual utilizando coronador para tapas tipo rosca. Las botellas se llenaron con aproximadamente $1 \mathrm{~L}$ de la bebida nutritiva de sacha inchic.

\section{Caracterización de las almendras y la bebida nutritiva}

Fueron realizados un análisis proximal ${ }^{7}$ de las almendras (semillas descascaradas) y la bebida nutritiva de sacha inchic, y un perfil de ácidos grasos de la bebida nutritiva. Los esteres metílicos de los ácidos grasos presentes en la bebida nutritiva fueron obtenidos siguiendo la metodología de Hartman y Lago ${ }^{8}$. La cuantificación de los ésteres fue realizada utilizando un cromatógrafo de gases (VARIAN 450-GC) en el Laboratorio de Sustancias Naturales Bioactivas del Instituto de Investigaciones de la Amazonía Peruana. Una descripción detalla del equipo puede ser consultada en García et al. ${ }^{9}$.

\section{Análisis de la actividad ureásica y sensorial de la almendra pre tostada}

El sabor agradable fue determinado por análisis sensorial a través del método afectivo, utilizando una escala hedónica de 5 puntos (5: me gusta mucho; 3: ni me gusta ni me 


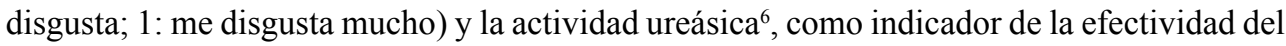
tratamiento térmico. Los datos fueron procesados mediante un diseño completamente al azar con un arreglo factorial de $2 \times 3$ con tres repeticiones, totalizando 18 ensayos. En este diseño la temperatura $\left(60\right.$ y $\left.80^{\circ} \mathrm{C}\right)$ y el tiempo $(4,5$ y 6 min.) fueron considerados como variables independientes y las variables dependientes fueron, sabor agradable (menor astringencia) y la actividad ureásica.

\section{Análisis sensorial de las suspensiones de la bebida de sacha inchic}

Las suspensiones de la bebida de sacha inchic obtenidas después de la etapa de estabilización fueron endulzadas para su evaluación sensorial a través del método afectivo. $\mathrm{O}$ atributo sabor (desagradable, amargo y astringente) fue evaluado mediante la aplicación de la prueba de preferencia por escala hedónica de 5 puntos (5: me gusta mucho; 3: ni me gusta ni me disgusta; 1: me disgusta mucho). Fue utilizado un diseño de bloques completamente al azar con comparaciones de medias de Tukey ( $5 \%$ de probabilidad).

\section{RESULTADOS Y DISCUSIÓN}

\section{Composición proximal de la almendra pre tostada}

La tabla 1 muestra la composición proximal de la almendra de sacha inchic (b.h.). Se observa un alto contenido en proteína $(35,01 \%)$ y grasa $(40,82 \%)$. Ruiz, et a ${ }^{10}$ reportaron contenidos de proteína de 29,6 \% y grasa 49,0 \%, utilizando almendras de la misma especie; Plukenetia volubilis Linneo, procedentes de la provincia San Martín, Perú. Las diferencias observadas pueden deberse a factores de cultivo tales como, fertilización, tipo de riego, entre otros.

Tabla 1. Composición proximal de almendras de sacha inchic.

\begin{tabular}{|c|c|}
\hline Análisis & \% (b.h.) \\
\hline Humedad & 7,62 \\
Proteína & 35,01 \\
Grasa & 40,82 \\
Fibra & 3,08 \\
Ceniza & 2,74 \\
Carbohidratos & 10,73 \\
\hline
\end{tabular}

\section{Análisis de la actividad ureásica y sensorial de la almendra pre tostada}

En la figura 1 se muestra el efecto de la temperatura y tiempo de pre-tostado en la sabor agradable (menor astringencia) de las almendras de sacha inchic. Es posible observar que a menor temperatura $\left(60^{\circ} \mathrm{C}\right)$ y mayor tiempo $(6 \mathrm{~min}$.) el sabor agradable es mayor, disminuyendo la percepción de la astringencia al incrementarse el tiempo de pre tostado. 


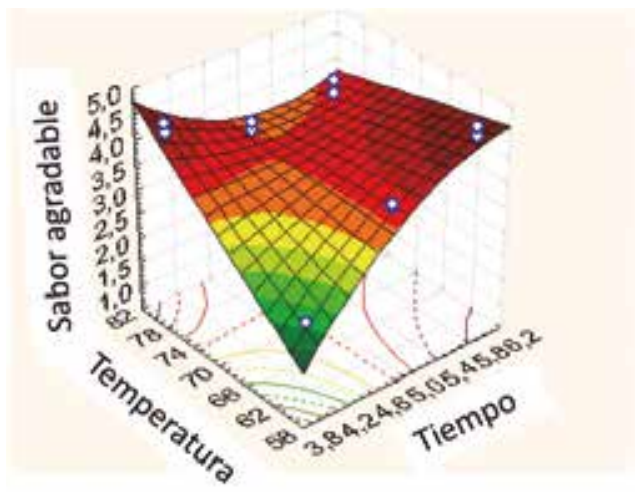

Figura 1. Superficie de respuesta de la influencia de la temperatura $\left({ }^{\circ} \mathrm{C}\right)$ y tiempo de pre tostado (min.) en el sabor agradable (escala hedónica de 5 puntos) de las almendras pre tostadas de sacha inchic.

El comportamiento es similar para la temperatura de pre tostado de $80{ }^{\circ} \mathrm{C}$, con la diferencia de mayor efectividad en la remoción de astringencia, que es confirmada con la prueba de actividad ureásica (tabla 2) concordando con lo reportado por Obregon ${ }^{4}$ y Salas $^{6}$, que mencionan que la efectividad de tratamiento térmico para la eliminación del sabor astringente es cuando el valor de la actividad ureásica es igual o menor a 0,03 del incremento de unidades de $\mathrm{pH}$; por consiguiente, la eliminación del sabor astringente en las semillas de sacha inchic se alcanza a partir de $60{ }^{\circ} \mathrm{C}$ y 6 minutos de pre tostado. Cisneros et al. ${ }^{11}$ realizaron estudios de la estabilidad oxidativa y capacidad anti-oxidativa de los aceites extraídos de semillas tostadas de sacha inchic. Los niveles de tostado estudiados fueron: levemente tostado (75$81^{\circ} \mathrm{C} / 9 \mathrm{~min}$.), medianamente tostado $\left(83-86^{\circ} \mathrm{C} / 10 \mathrm{~min}\right.$.) y altamente tostado $\left(99-102{ }^{\circ} \mathrm{C}\right.$ / 10min.). En este estudio, se determinó que el efecto del tostado de las semillas favoreció sus características sensoriales de aprobación, eliminando el sabor astringente. Además, en el mismo estudio se concluyó que el proceso de tostado de las semillas de sacha inchic ocasiona un ligero incremento de los indicadores de oxidación en el aceite obtenido. El valor de peróxido, que originalmente en aceite de semillas sin tostar es de 0,57 $\pm 0,01 \mathrm{meq} / \mathrm{kg}$ de aceite, es incrementado hasta un valor de 3,35 $\pm 0,04 \mathrm{meq} / \mathrm{kg}$ de aceite, para semillas ligeramente tostadas.

Tabla 2. Índice de actividad ureásica como unidades de $\mathrm{pH}$ de almendras de sacha inchic en función de la temperatura y tiempo de pre tostado.

\begin{tabular}{|c|c|c|}
\hline \multicolumn{2}{|c|}{ Índice de actividad ureásica (incremento de unidades de $\mathbf{p H})$} \\
\hline \multirow{2}{*}{ Tiempo (min) } & \multicolumn{2}{|c|}{ Temperatura $\left({ }^{\circ} \mathbf{C}\right)$} \\
\cline { 2 - 3 } & $\mathbf{6 0}$ & $\mathbf{8 0}$ \\
\hline $\mathbf{4}$ & 0,07 & 0,00 \\
$\mathbf{5}$ & 0,05 & 0,02 \\
$\mathbf{6}$ & 0,03 & 0,00 \\
\hline
\end{tabular}


A partir de los resultados del análisis de la actividad ureásica y sensorial de la almendra pre tostada se concluye que la condición más adecuada del pre tostado de las semillas de sacha inchic es a una temperatura de $60{ }^{\circ} \mathrm{C}$ durante $6 \mathrm{~min}$.

\section{Análisis sensorial de las suspensiones de la bebida de sacha inchic}

La figura 2 muestra el resultado del análisis sensorial (atributo sabor) de la bebida nutritiva a partir de las relaciones almendra: agua (p/v) (1:3, 1:4 y 1:5), donde sobresale la relación almendra: agua de 1:3 con 82,6 \% de aceptación (promedio de la prueba de Tukey =4,13).

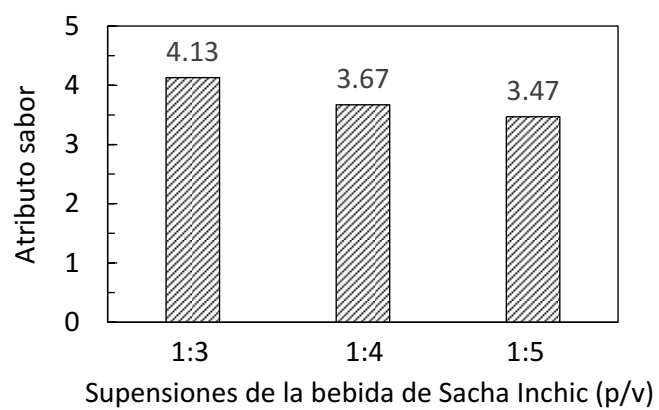

Figura 2. Promedios de la prueba de Tukey ( $5 \%$ de probabilidad) para el atributo sabor (escala hedónica de 5 puntos) vs. suspensiones ( $\mathrm{p} / \mathrm{v}$ ) de la bebida nutritiva de sacha inchic.

\section{Caracterización de la suspensión de la bebida nutritiva de sacha inchic}

La relación almendra: agua $(\mathrm{p} / \mathrm{v})$, fue evaluada por la cuantificación de propiedades físicos químicas (sólidos totales, densidad, viscosidad aparente y acidez titulable) de la suspensión de la bebida nutritiva tal como se muestra en la tabla 3, donde se puede observar que la relación 1:3 (p/v) alcanza $11,6 \%$ de solidos totales. Este valor es similar a los sólidos totales de la leche soya reportados en otros estudios ${ }^{6,11}$. (12\% y 9,45\%, respectivamente). Felberg et al. ${ }^{12}$, en su estudio de caracterización fisicoquímica de bebidas de extracto de soya y extracto de castaña de Brasil, obtuvieron valores de 9,92 \% y 13,6 \% de sólidos totales, respectivamente. Cabe mencionar que los valores de sólidos totales del extracto de soya pueden estar influenciados por la composición de los granos, método de preparación, contenido inicial de humedad, grado de trituración y dilución. Siguiendo esta premisa, los valores de los sólidos totales de la bebida nutritiva de sacha inchic podrían también presentar estas variaciones. Respecto a la densidad, la bebida nutritiva de sacha inchic para todas las relaciones (tabla 3 ), es similar a la leche de soya ${ }^{13}(1,027 \mathrm{~g} / \mathrm{mL})$. Sin embargo, su viscosidad difiere de la leche de soya, que es igual a $21 \mathrm{cP}$ a $20^{\circ} \mathrm{C}^{13}$. 
Tabla 3. Propiedades físico químicas de las suspensiones de la bebida nutritiva de sacha inchic.

\begin{tabular}{|c|c|c|c|}
\hline \multirow{2}{*}{ Propiedades físico químicas } & \multicolumn{3}{|c|}{ Suspensión de la bebida nutritiva de } \\
& \multicolumn{3}{|c|}{ sacha inchic } \\
\cline { 2 - 4 } & $\mathbf{1 : 3}$ & $\mathbf{1 : 4}$ & $\mathbf{1 : 5}$ \\
\hline Sólidos totales (\%) & 11,6 & 9,93 & 5,60 \\
\hline Densidad $(\mathrm{g} / \mathrm{mL})$ & 1,095 & 1,012 & 1,007 \\
\hline Viscosidad aparente $(\mathrm{cP})$ a $29^{\circ} \mathrm{C}$ & 12,6 & 11,9 & 11,7 \\
\hline $\begin{array}{c}\text { Acidez titulable }(\mathrm{ml} \text { de ácido } \\
\text { sulfúrico) }\end{array}$ & 0,07 & 0,049 & 0,032 \\
\hline
\end{tabular}

La tabla 4 muestra la composición proximal de la bebida nutritiva de sacha inchic, donde se observa que el contenido de proteína es similar al extracto de soya reportado por Fulberg et $a l .{ }^{12}$; en cuanto al contenido de grasa es superior al extracto de soya, sin embargo, similar al contenido de grasa del extracto de castaña de Brasil. Adicionalmente, la bebida nutritiva posee $79,69 \mathrm{kcal} / 100 \mathrm{~g}$ de energía total.

Tabla 4. Composición proximal de bebida nutritiva de sacha inchic comparada con las composiciones de bebidas de extracto de soya y castaña de Brasil.

\begin{tabular}{|c|c|c|c|}
\hline $\begin{array}{l}\text { Análisis en } \\
\text { base g/100g }\end{array}$ & $\begin{array}{l}\text { Bebida nutritiva } \\
\text { de sacha inchic }\end{array}$ & $\begin{array}{c}\text { Bebida de soya } \\
\text { integral }^{(12)}\end{array}$ & $\begin{array}{c}\text { Bebida de castaña de } \\
\text { Brasil integral }^{(12)}\end{array}$ \\
\hline Humedad & 88,70 & -- & -- \\
\hline Proteína & 3,3 & 2,69 & 1,75 \\
\hline Grasa & 7,13 & 1,96 & 7,20 \\
\hline Ceniza & 0,29 & 0,48 & 0,52 \\
\hline Carbohidratos & 0,58 & 4,79 & 4,13 \\
\hline Sólidos totales & 11,6 & 9,92 & 13,6 \\
\hline
\end{tabular}

La tabla 5 muestra los ácidos grasos presentes en la bebida nutritiva de sacha inchic. Merino ${ }^{14}$ reportó valores de 40,43\% de ácido linolénico, 41,09\% de ácido linoleico y 10,06\% de ácido oleico, para el aceite proveniente de la almendra sin ningún tratamiento térmico. En otro estudio, Arana y Paredes ${ }^{15}$ reportaron análisis en aceites de almendra que recibieron tratamiento térmico a $77^{\circ} \mathrm{C}, 85,2^{\circ} \mathrm{C}$ y $101,2^{\circ} \mathrm{C}$, concluyendo que la temperatura no influye significativamente en la composición de ácidos grasos en el aceite de sacha inchic. 
Tabla 5. Ácidos grasos presentes en la bebida nutritiva de sacha inchic.

\begin{tabular}{|l|c|}
\hline \multicolumn{1}{|c|}{ Ácidos graso } & $\%$ \\
\hline Ácido palmítico (C16:0) & $3,83 \pm 0,17$ \\
Ácido palmitoleico (C16:1) & $2,31 \pm 0,14$ \\
Ácido oleico (C18:1) & $8,16 \pm 0,02$ \\
Ácido linoleico (C18:2) & $30,93 \pm 0,11$ \\
Ácido linolénico (C18:3) & $42,19 \pm 0,18$ \\
Total de ácidos grasos insaturados & 81,28 \\
\hline
\end{tabular}

\section{CONCLUSIONES}

Técnicamente, es factible obtener una bebida nutritiva de sacha inchic, pre tostando las semillas a $60{ }^{\circ} \mathrm{C}$ por 6 min y considerando una relación almendra: agua de 1:3. En este procedimiento, la temperatura y tiempo de pre tostado utilizados fueron parámetros relevantes para la eliminación del sabor astringente en las almendras de sach inchic. La determinación de la actividad ureásica confirmo la importancia del manejo adecuados de estos parámetros. La bebida nutritiva obtenida aporta 3,3\% proteína, 7,13\% de grasa, 11,6 \% de sólidos totales y altos niveles de ácidos grasos esenciales (30,9\% de ácido linoléico y 42,19\% de ácido linolénico). Este perfil nutricional asociado a los resultados positivos del análisis sensorial muestran que el consumo de la bebida nutritiva de sacha inchic podría considerarse como una alternativa al consumo de la leche de vaca.

\section{BIBLIOGRAFÍA}

1. Rodríguez A, Corazón-Guivin M, Cachique D, Mejía K, Del Castillo D, Renno JF, et al. Diferenciación morfológica y por ISSR (Inter simple sequence repeats) de especies del género Plukenetia (Euphorbiaceae) de la Amazonia Peruana: propuesta de una nueva especie. Rev Per Biol. 2010; 17(3): 325-330.

2. Valles CR. Potencial Agro Alimentario Industrial de Sacha Inchic para la Selva alta. Tarapoto: Universidad de San Martin; 1991.

3. Sathe SK, Kshirsagar HH, Sharma GM. Solubilization, fractionation, and electrophoretic characterization of Inca peanut (Plukenetia volubilis L.) proteins. Plant Foods Hum Nutr 2012; 67(3): 247-255.

4. Obregón A. Obtención de Sacha Inchic (Plukenetia volubilis) en polvo secado por atomización. [Tesis Maestría]. Lima: Universidad Nacional Agraria La Molina - Perú; 1996. 
5. Chirinos R, Zorrilla D, Aguilar-Galvez A, Pedreschi R, Campos D. Impact of Roasting on Fatty Acids, Tocopherols, Phytosterols, and Phenolic Compounds Present in Plukenetia huayllabambana Seed [Internet]. J Chem. 2016 [citado 4 de octubre de 2017]. Disponible en: https://www.hindawi.com/journals/jchem/2016/6570935/

6. Salas F. Obtención de bebida de Soya en polvo a partir del frejol de soya integral. [Tesis]. Lima: Universidad Nacional Agraria La Molina, Lima- Perú; 1981.

7. Firestone D, Perez M. Oils and fat. En: Official Methods and Analysis. 19th ed. Gaithersburg, MD: AOAC International; 2012.

8. Hartman L, Lago RC. Rapid preparation of fatty acid methyl esters from lipids. Lab Pract. 1973;22(6):475-476

9. García D, Seclen A, Rengifo D, Saldaña R, Dávila E, Merino C, et al. Obtención de lípidos estructurados a partir de mezclas binarias de aceites de castaña (Bertholletia excelsa) y sacha inchi (Plukenetia volubilis L.). Rev Soc Quím Perú. 2013; 79(4):359366.

10. Ruiz C, Díaz C, Anaya J, Rojas R. Análisis proximal, antinutrientes, perfil de ácidos grasos y de aminoácidos de semillas y tortas de 2 especies de Sacha Inchi (Plukenetia volubilis y Plukenetia huayllabambana). Rev Soc Quím Perú. 2013; 79(1): 29-36.

11. Cisneros FH, Paredes D, Arana A, Cisneros-Zevallos L. Chemical Composition, Oxidative Stability and Antioxidant Capacity of Oil Extracted from Roasted Seeds of Sacha-Inchi (Plukenetia volubilis L.). J Agric Food Chem. 2014; 62, 5191-5197.

12. Felberg I, Deliza R, Gonçalvez EB, Antoniassi R, Freitas SD, Cabral LC. Bebida mista de extrato de soja integral e castanha-do-brasil: caracterização físico-química, nutricional e aceitabilidade do consumidor. Alim Nutr. 2004; 15(2): 163-174.

13. Wang S, Cabral L; Araujo F; Maia L. Características Sensoriais de Leites de Soja Reconstituídos. Pesq Agropec Bras.1999; 34(3): 467-472.

14. Merino C. Caracterización de ácidos grasos y aminoácidos de diez ecotipos de Plukenetia volubilis L. (Sacha Inchi) de la Amazonia Peruana. [Tesis]. Iquitos: Universidad Nacional de la AMAZONÍA peruana; 2009.

15. Arana A, Paredes D. Estabilidad oxidativa y capacidad antioxidante del aceite de Sacha Inchi (Plukenetia volubilis L.) extraído de semillas tostadas a diferentes condiciones. [Tesis]. Lima: Universidad San Ignacio de Loyola; 2008. 